Br Heart J 1989;61:144-8.

3 Lee $\mathrm{CH}$, Xiao HB, Gibson DG. Presystolic tricuspid valve closure: An alternative mechanism of diastolic sound genesis. Cardiology 1990;77:340-5.

4 Laennec RTH. Traité de l'auscultation médiate. 2nd ed. Paris: Brosson et Chaude, 1826

5 Ozawa Y, Smith D, Craige E. Origin of the third heart sound: I. Studies in dogs. Circulation 1983;67:393-8.

6 Ozawa Y, Smith D, Craige E. Origin of the third hear sound: II. Studies in human subjects. Circulation

7 Tyberg TI, Goodyer AVN, Langou RA. Genesis of a pericardial knock in constrictive pericarditis. Am Cardiol 1980;46:570-5.
8 Lee $\mathrm{CH}$, Gibson DG. Isovolumic relaxation sound: a new class of added heart sound? Br Heart J 1991;65:357-9.

9 Traill TA, Fortuin N. Presystolic mitral closure sound in aortic regurgitation with left ventricular hypertrophy and aortic regurgitation with left ventricular hypertrophy
first degree heart block. Br Heart J 1982;48:78-80.

10 Mackenzie J. Valvular defects (continued). In: Mackenzie J ed. Diseases of the heart. London: Oxford University Press,

11 Groedel FM, Miller M. Studies on the acoustic phenomen over the vessels of the neck in the healthy and diseased heart. Exper Med Surg 1944;11:193-215.

12 Dock W. Loud presystolic sounds over the jugular veins associated with high venous pressure. $\mathrm{Am} \mathrm{J} \mathrm{Med} 1956$ 20:853-9.

\title{
Prediction of sudden death in hypertrophic cardiomyopathy
}

Abnormalities of heavy chain myosin account for perhaps $50 \%$ of hypertrophic cardiomyopathy (HCM). It now seems that the site and nature of the aminoacid change influence survival. Why should this be? One possibility is that the substitutions interfere to a different degree in myofibrillary organisation within the myocyte. It is probably significant that the substitution leading to a change in charge has the greatest deleterious effect on survival. Abnormal myofibrillary organisation probably leads in turn to misshapen cells and abnormalities in cell to cell organisation producing disarray and an ideal substrate for arrhythmias. Family history remains a cheap way of identifying those with HCM at high risk of sudden premature death but a good case can be made for determining the exact gene abnormality. The understanding of how HCM affects myocyte structure will be further forwarded when the other genes unrelated to heavy chain myosin are discovered. These are exciting times for those interested in HCM.

M J DAVIES

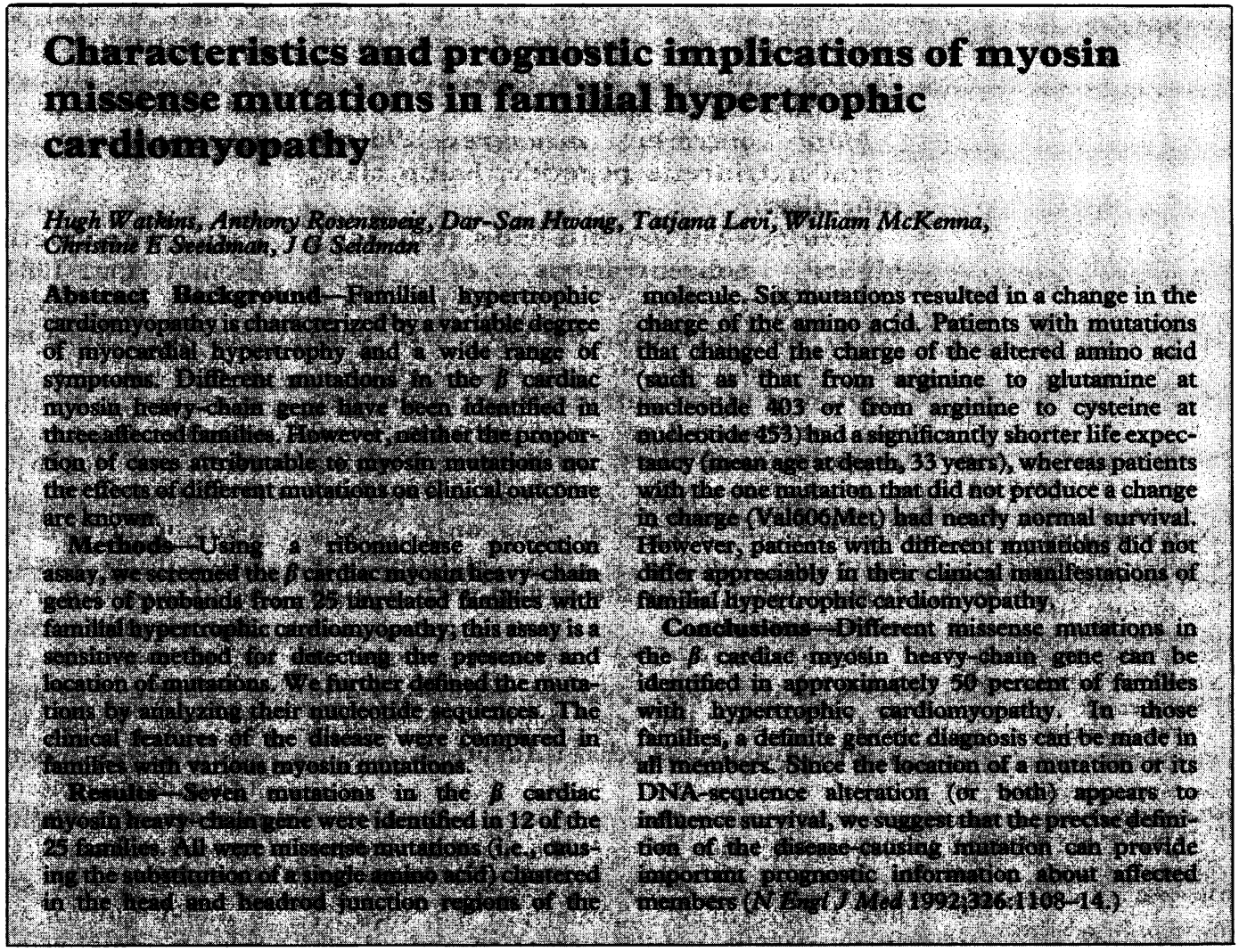

